\title{
SYNTHESIS OF ZEOLITE-A USING KAOLIN SAMPLES FROM DARAZO, BAUCHI STATE AND AJEBO, OGUN STATE IN NIGERIA
}

\author{
H. E. Mgbemere ${ }^{1,}{ }^{*}$, G. I. Lawal ${ }^{2}$, I. C. Ekpe ${ }^{3}$ and A. L. Chaudhary ${ }^{4}$

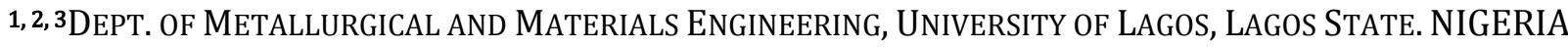 \\ ${ }^{4}$ Institute OF Materials Research, Helmholtz Zentrum GeESTHaCht MaX Planck Strasse 1, \\ GEESTHACHT 21502 GEESTHACHT, GERMANY

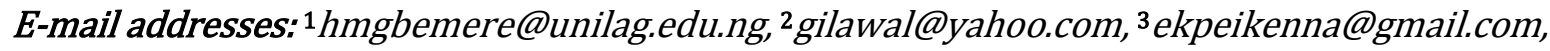 \\ 4anna-Lisa.Chaudhary@hzg.de
}

\begin{abstract}
Kaolin samples from Ajebo and Darazo in Nigeria were characterized and used to produce zeolite-A crystals. The thermal analysis indicates that both samples undergo de-hydroxylation from $450{ }^{\circ} \mathrm{C}$ to about $700{ }^{\circ} \mathrm{C}$ and are converted to metakaolin with a weight loss of about 11.39 and $10.43 \%$ for the Ajebo and Darazo samples respectively. Characteristic $\mathrm{OH}, \mathrm{Al}-\mathrm{OH}, \mathrm{Si}-\mathrm{OH}$ and Si-O-Al bands were confirmed in both samples with Infra-red spectroscopy studies. The $X$-ray diffraction patterns clearly show the presence of the characteristic peaks (12.35 and 24.88 ) of kaolinite with little quartz impurities. $X$-ray diffraction measurements $\left(2 \theta\right.$ peaks at $7-18^{\circ}$ and $\left.21-35^{\circ}\right)$ and scanning electron micrographs clearly show that zeolite-A crystals are produced. The microstructures of kaolin, metakaolin and zeolite-A crystals reveal the presence of platy crystals, amorphous spherical aggregates and cubic-shaped crystals with some amorphous gel respectively. The results show that both Ajebo and Darazo kaolin are suitable for zeolite-A synthesis.
\end{abstract}

Keywords: Kaolin, Metakaolin, Thermal analysis, X-ray Diffraction, Zeolite- $A$

\section{INTRODUCTION}

Clay minerals such as kaolinite, smectite, vermiculite, mica, chlorite and palygorskite and sepiolite groups are very useful naturally occurring minerals of which kaolinite $\left(\mathrm{Al}_{2} \mathrm{Si}_{2} \mathrm{O}_{5}(\mathrm{OH})_{4}\right)$ is one of the most important [1-3]. Raw kaolin contains kaolinite as the main mineral phase, white mica (muscovite and newly formed illite or mixed-layer structures of illite and smectite), quartz and residues of un-decomposed silicates, mostly feldspar, biotite and accessory minerals. These accessory minerals can be divided into original (e.g. tourmaline, zircon, garnet, ilmenite and rutile) and newly formed minerals (e.g. siderite, pyrite, marcasite, chlorite, goethite, akaganeite, hematite, anatase and rutile) [1].

Kaolin is a weathering product of silicate rocks whose colour ranges from whitish to earthy with certain degrees of plasticity. It is widely used as an industrial mineral for the production of ceramics, refractories and as an industrial filling material for paper, rubber, plastics, dyes and paints [1, 3, 4]. Furthermore, kaolin can be utilized for waste management $[5,6]$ and in the preparation of geopolymers and geopolymer-based composites [7-9], zeolites $[10,11]$ and intercalates $[12$, 13].

Kaolin is a naturally occurring mineral of the clay family and may contain a number of impurities such as quartz, feldspar, tourmaline, ilmenite, zircon, etc., which are derived from the parent rock [14]. The structure and properties of kaolinite, the main mineral phase of kaolin, have been studied using different tools. Brindley and Robinson [15] are among the first researchers to investigate the structure of kaolinite. They measured the X-ray diffraction patterns of kaolinite samples from different locations and used the results from the analyses of the reflections, lattice parameters etc. to determine the structure of kaolin. Karmous [16] used a computational energy minimization technique to show that the total lattice energy in kaolinite is equal to $-827.4 \mathrm{eV}$ while the primitive cell volume is $321.3 \AA$ A . Using first principle calculations, Militzer et al.,[17] calculated the elastic constants of kaolinite and showed their possible application areas. With Rietveld refinement, Young and 
Hewat [18] verified that the crystal structure of kaolinite is triclinic. Kaolin deposits are found in significant quantities in virtually all parts of Nigeria. According to the Raw Materials Research and Development Council of Nigeria (RMRDC), there are about 800 tonnes of proven deposits in Nigeria [14, 19].

The properties of these kaolin minerals are mostly affected by the orderliness of the kaolinites and a poorly ordered structure is explained to be due to stacking faults in the material. Differential thermal analysis and thermogravimetric methods are used to determine the degree of order. While the later shows the quantity of volatile matter in the kaolinite that is lost during heating, the thermal analysis uses exothermic and endothermic reactions during heating to check the degree of order or disorder.

Although a few researchers, such as Edomwonyi-Out et al. [20-22, 52] have investigated the influence of thermal treatment on Kankara kaolinite in Nigeria, an in-depth understanding of the properties and possible application areas for this and other kaolinite deposits is still lacking.

Kaolin has been used to synthesize zeolite-A in the literature [23-27]. Ugal et al., [27] used Iraqi kaolin to synthesize zeolite type $4 \mathrm{~A}$. Ion exchange technique was used to insert sodium to the structure and tests carried out indicate that the zeolite can be used for water adsorption purposes. Zhao et al., [28] also used halloysite mineral to produce well-ordered $\mathrm{NaA}$ zeolite. The zeolite displayed a faster adsorption rate and capacity for removing ammonium ions from wastewater. Zeolite Y and ZSM-5 have been produced from Ahoko clay while zeolite ZSM-11 has been produced from kaolinite clay from Nigeria" $[29,51]$. They showed that very long calcination time is not necessary as calcination at $600{ }^{\circ} \mathrm{C}$ for 6 minutes is enough to produce metakaolin.

The goal of this work is therefore, to investigate the characteristics (structural order, composition etc.) of kaolin samples from Ajebo and Darazo in Nigeria. It also aims to produce zeolite-A from the kaolin samples and to compare the zeolite produced with the zeolite- $A$ samples in the literature.

\section{MATERIALS AND METHODS}

\subsection{Sample Preparation}

The kaolin samples used in the present investigation were collected from Ajebo in Ogun State and Darazo in Bauchi State Nigeria. $8000 \mathrm{~g}$ each of both samples were soaked in 15 litres of water for $24 \mathrm{~h}$ to form slurry, dissolve impurities and other unwanted materials present. The top surface water was decanted and the slurry was subsequently sieved with a sieve of mesh size $350 \mu \mathrm{m}$ and dried. The dried cake was pulverized and sieved to allow only particles with sizes $\leq 100$ $\mu$ mto pass through. The meta-kaolinization process was carried out by subjecting the samples to elevated temperatures ranging from $600^{\circ} \mathrm{C}$ to $900^{\circ} \mathrm{C}$ for $2 \mathrm{~h}$ using a muffle furnace.

Synthesis of the zeolite-A was carried out using the metakaolin samples calcined at $700^{\circ} \mathrm{C}$ and $900^{\circ} \mathrm{C}$ while $\mathrm{NaOH}$ pellets were the source of $\mathrm{Na}_{2} \mathrm{O} .5 \mathrm{~g}$ of $\mathrm{NaOH}$ was dissolved in $72 \mathrm{~g}$ of deionized water and stirred briefly for 10 minutes. $4.1 \mathrm{~g}$ of metakaolin was then gradually added to obtain the aluminosilicate gel. The gel was continuously stirred at room temperature and allowed to age for 24 hours

A hydrothermal treatment was performed in an oven maintained at $120^{\circ} \mathrm{C}$ for 6 hours. At the end of the hydrothermal reaction, the mixture was filtered and washed with deionized water until a $\mathrm{pH}$ of about 7 was obtained and dried in an oven at $100^{\circ} \mathrm{C}$ for 4 hours. The zeolite obtained was then characterized using FTIR, Xray diffraction and Scanning Electron Microscope.

\subsection{Sample Characterization}

Chemical analysis of the samples was performed using X-ray fluorescence spectroscopy while the particle size analysis of the samples was carried out using a particle size analyser (Mastersizer 3000 Malvern Instruments Ltd, Malvern UK). The samples were dissolved in ethanol and made to pass through laser light which diffracts the particles. The Atterberg's limit test was used to measure the plasticity of the samples in accordance with the ASTM 4318 standard[30]. The samples were rolled out into threads and a manual rollout test was used to determine the plasticity index which indicates the difference between the liquid and plastic limit of the samples. The thermal analyses (Differential Thermal Analysis and Thermogravimetric (DTA/TG) analysis) were carried out from $30^{\circ} \mathrm{C}$ to 700 ${ }^{\circ} \mathrm{C}$ at a heating rate of $5{ }^{\circ} \mathrm{C} /$ minutes. This was done using a Netzsch STA 409 C (NetzschGmbH \& Co. KG Selb, Germany) in $50 \mathrm{~mL} /$ minutes argon flow.

The X-ray diffraction measurements were carried out with a scanning range of $2 \theta$ values from $10^{\circ}-80^{\circ}$ with an increment of $8.75{ }^{\circ}$ and an exposure time of 400 seconds per step. The X-ray diffraction (XRD) tests were carried out with a Bruker D8 Discover diffractometer (Bruker AXS, Karlsruhe, Germany) with CuK $\alpha$ radiation $(\lambda=1.54056 \AA)$ with a current of 1000 $\mu \mathrm{A}$ and a voltage of $50 \mathrm{kV}$. The powder was finely ground by hand using a mortar and pestle and placed onto a commercial sample holder. The Fourier Transform Infrared spectroscopy was carried out with a SchimadzuIR Affinity-1S (Schimadzu Corporation, Japan). The powder samples were pressed into pellets by mixing dried $\mathrm{KBr}$ and the powder and placing them in a pre-heated die under a heat lamp. The 
measurements were made in transmission mode and peaks were reported based on percentage transmittance to given wavelengths. The morphology of the samples was measured using a scanning electron microscope (ASPEX 3020, Aspex Corporation). The samples were put into a sample chamber and sputtered with gold for electrical contact. The Secondary electron imaging mode was used to acquire the images.

\section{RESULTS AND DISCUSSION}

\subsection{Plasticity}

Table 1 shows the result of the liquid limit, plastic limit and the plasticity index for the kaolin samples. The sample from Darazo has a liquid limit, plastic limit and plasticity index of $34.35,25.31$ and 9.04 respectively while the sample from Ajebo has a liquid limit, plastic limit and plasticity index of 37.08, 23.88 and 13.2 respectively. The obtained values for both samples indicate that they are moderately plastic. The plasticity (or workability) index for Ajebo kaolin is however slightly higher than that of Darazo kaolin, an indication that Ajebo clay will be easier to work than the Darazo kaolin. Based on the diagram by Hajjaji et al. which classifies different soil samples on the basis of their workability, both Ajebo and Darazo kaolin are moderate plastic clays and their plasticity index values fit the space that is allocated to kaolinite samples [31].

Table 1: Atterberg's limit variation for Ajebo and Darazo kaolin

\begin{tabular}{lll}
\hline & Darazo & Ajebo \\
\hline Liquid Limit & 34.35 & 37.08 \\
Plastic Limit & 25.31 & 23.88 \\
Plasticity Index & 9.04 & 13.2 \\
\hline
\end{tabular}

\subsection{Chemical Analysis}

The composition of the various compounds in the kaolin samples are shown in Table 2. In both samples, the major compounds are $\mathrm{SiO}_{2}$ and $\mathrm{Al}_{2} \mathrm{O}_{3}$. For Ajebo kaolin, the $\mathrm{SiO}_{2}$ and $\mathrm{Al}_{2} \mathrm{O}_{3}$ amounts are 45.87 and $39.96 \%$ respectively while in the Darazo sample the values are 46.18 and $40.20 \%$ respectively. The chemical analysis also shows trace amounts of $\mathrm{Fe}_{2} \mathrm{O}_{3}$ in the samples, not more than 0.3 wt.\%. Compared with the formula for the ideal kaolinite $\left(\mathrm{Al}_{2} \mathrm{Si}_{2} \mathrm{O}_{5}(\mathrm{OH})_{4}\right.$, the chemical composition of the two major compounds in the kaolinite samples have been calculated to be $\mathrm{Al}_{2.008} \mathrm{Si}_{1.98} \mathrm{O}_{4.96}(\mathrm{OH})_{4.01}$ and $\mathrm{Al}_{2.01} \mathrm{Si}_{1.99} \mathrm{O}_{4.98}(\mathrm{OH})_{3.98}$ for the Ajebo and Darazo samples respectively. The $\mathrm{SiO}_{2} / \mathrm{Al}_{2} \mathrm{O}_{3}$ ratio is approximately 1 and this makes the samples suitable for direct use in the synthesis of zeolites.

\subsection{Particle Size Analysis}

The particle size distribution measurements of the powders are shown in Figure 1. The measurements were carried out 5 times for both samples to improve measurement statistics. The mean and standard deviation values were calculated to determine the validity of the sample sizes. For most particle size distribution experiments, $d_{10}, d_{50}$ and $d_{90}$ respectively are parameters used to define the size of powders. $d_{10}$ represents sizes $\leq 10 \%, d_{50}$ stands for $\leq 50 \%$ and $d_{90}$ $\leq 90 \%$ of the powders below a certain size. For Ajebo kaolin, the $d_{10}, d_{50}$ and $d_{90}$ are $0.4308 \pm 0.004 \mu \mathrm{m}$, $1.0518 \pm 0.0369 \mu \mathrm{m}$ and $7.184 \pm 0.3484 \mu \mathrm{m}$ respectively while for Bauchi kaolin, the $d_{10}, d_{50}$ and $d_{90}$ are $0.4576 \pm 0.0039 \mu \mathrm{m}, 1.156 \pm 0.028 \mu \mathrm{m} \quad$ and $9.178 \pm 0.0763 \mu \mathrm{m}$ respectively.

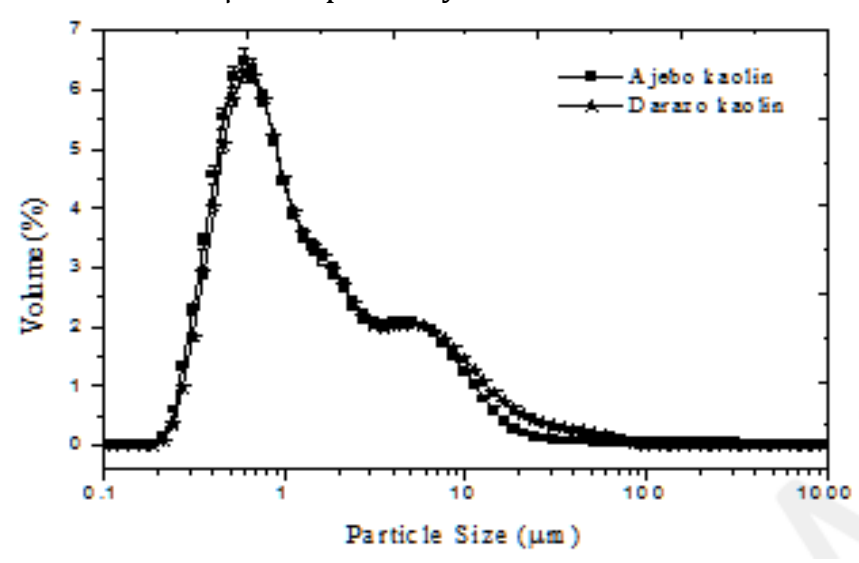

Figure 1: Graph showing the particle size distribution of Ajebo and Darazo kaolin. The graphs show that a bimodal size distribution exists in the samples.

\subsection{Fourier Transform Infrared Spectroscopy (FTIR)}

The FTIR spectra of the kaolin samples from Ajebo and Darazo are shown in Figure 2. Both samples have very similar band assignments which is an indication of similar constituents as shown in Table 2. At room temperature, the $\mathrm{OH}$ bands, $\mathrm{Al}-\mathrm{O}, \mathrm{Si}-\mathrm{O}$ bands etc. can clearly be observed. After calcining the sample at 600 ${ }^{\circ} \mathrm{C}$, the IR spectrum indicates that some degree of dehydroxylation has taken place but the process is not complete.

Table 2: Table showing the composition of Ajebo and Darazo kaolin (Compound Amounts (weight \%))

\begin{tabular}{lllllllll}
\hline & $\mathrm{SiO}_{2}$ & $\mathrm{Al}_{2} \mathrm{O}_{3}$ & $\mathrm{Fe}_{2} \mathrm{O}_{3}$ & $\mathrm{CaO}$ & $\mathrm{MgO}$ & $\mathrm{Na}_{2} \mathrm{O}$ & $\mathrm{MnO}$ & L.O.I \\
\hline Ajebo & 45.87 & 39.96 & 0.30 & 0.31 & 0.19 & 0.12 & 0.002 & 11.3 \\
Darazo & 46.18 & 40.20 & 0.19 & 0.36 & 0.21 & 0.10 & 0.00 & 10.80 \\
\hline
\end{tabular}



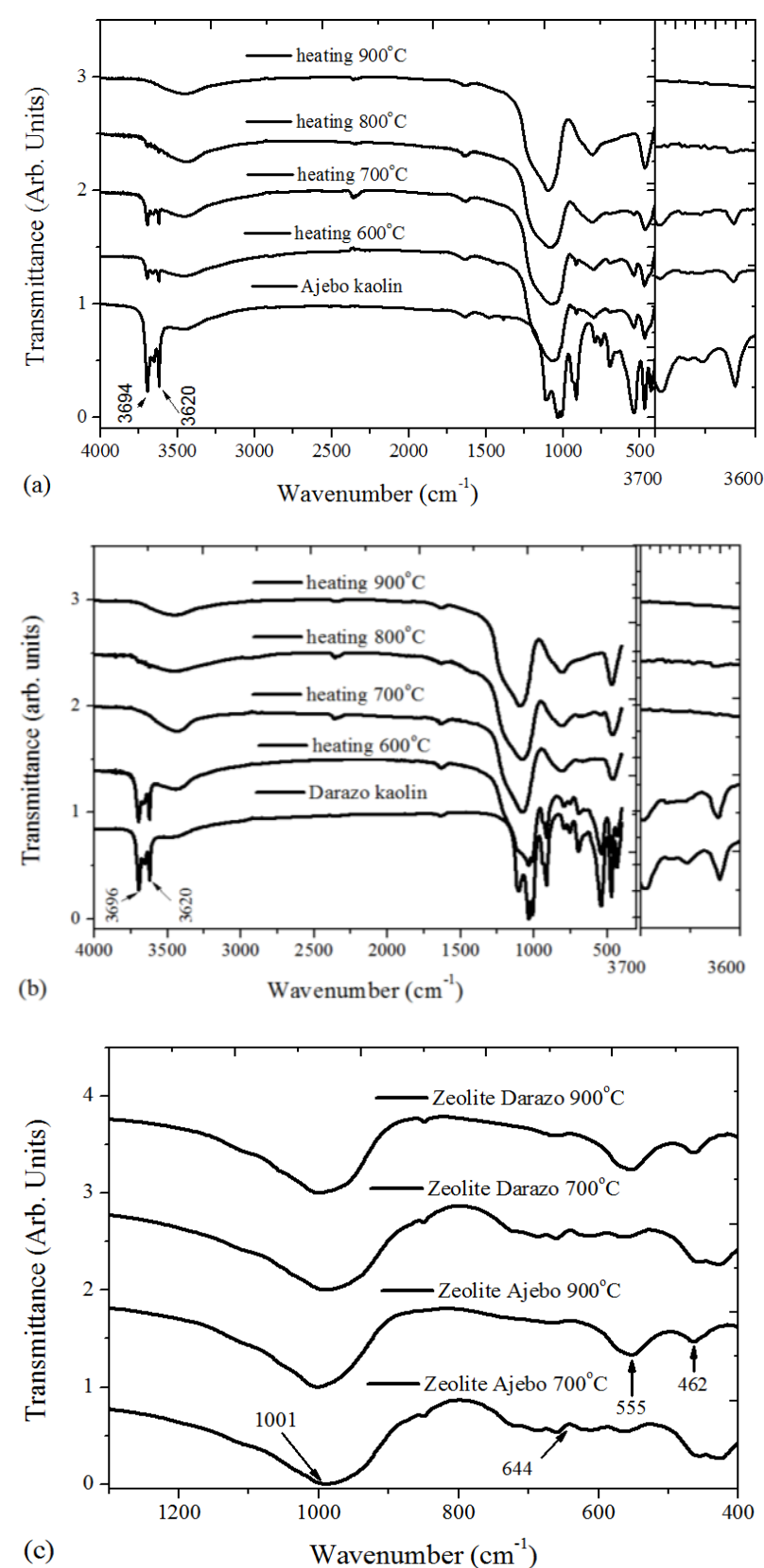

Figure 2: Fourier Transform Infrared spectra of (a) Ajebo kaolin at room temperature and samples calcined at temperatures between $600{ }^{\circ} \mathrm{C}$ and $900^{\circ} \mathrm{C}$ and (b) Darazo kaolin at room temperature and of samples calcined at temperatures between $600{ }^{\circ} \mathrm{C}$ and $900{ }^{\circ} \mathrm{C}$ (c) Zeolite-A samples from metakaolin at $700^{\circ} \mathrm{C}$ and $900{ }^{\circ} \mathrm{C}$ respectively. The inset on the right is an enlargement of the wavenumbers between $3600 \mathrm{~cm}^{-1}$ and $3700 \mathrm{~cm}^{-1}$ showing the $\mathrm{OH}$ bands in kaolin

On heating to $700{ }^{\circ} \mathrm{C}$, the spectrum shows that the Darazo kaolin has completely de-hydrolysed but the Ajebo kaolin has not. Above $700{ }^{\circ} \mathrm{C}$, the process becomes completed for both samples and the metakaolin is believed to have been fully formed. The differences in positioning and relative intensities of the
$-\mathrm{OH}$ stretching and bending bands in the infra-red spectrum of kaolinite gives an indication of how the structures are ordered [32]. Vaculíková, et al.[33] classified the degree of ordering into three types: Ordered if the $\mathrm{OH}$ stretching and bending bands are clearly resolved; partially ordered, if the individual $\mathrm{OH}$ bands at $3670 \mathrm{~cm}^{-1}, 3650 \mathrm{~cm}^{-1}$ and $938 \mathrm{~cm}^{-1}$ have low intensities and Poorly ordered if only one band near $3660 \mathrm{~cm}^{-1}$ or inflexions near $3670 \mathrm{~cm}^{-1}, 3650 \mathrm{~cm}^{-1}$ and $938 \mathrm{~cm}^{-1}$ are observed. The Ajebo and Darazo Kaolinite are ordered since the $\mathrm{OH}$ stretching and bending bands are clearly resolved.

Four sharp stretching bands between 3600 and 3700 $\mathrm{cm}^{-1}$ are normally used to identify the $-\mathrm{OH}$ bands in kaolin [34-38]. These four $\mathrm{OH}$ bands in the spectra of Ajebo and Darazo kaolinite have two sharp characteristic peaks at approx. 3620.51 and 3695.73 $\mathrm{cm}^{-1}$ and a weak doublet peak. The inset on the right is an enlargement of the $-\mathrm{OH}$ bands that are typical in kaolin samples. The strong characteristic peaks at $3695.73 \mathrm{~cm}^{-1}$ arises from surface hydroxyls and produces an in-phase vibration perpendicular to the 1:1 layers in kaolin [39].

The two weak peaks at $3670 \mathrm{~cm}^{-1}$ and $3652 \mathrm{~cm}^{-1}$ are due to stretching vibrations that are sub-parallel to the 1:1 layers whereas the low frequency $3620.51 \mathrm{~cm}^{-1}$ is assigned to the fourth $\mathrm{OH}$ inner group. The bands at wavenumbers $3620-3630 \mathrm{~cm}^{-1}$ are due to the $-\mathrm{OH}$ groups bonding into octahedral sheets, and it constitutes $1 / 4$ of the $-\mathrm{OH}$ groups in the mineral, while the bands of $3690-3698 \mathrm{~cm}^{-1}$ belong to the $-\mathrm{OH}$ groups bonding on the face of the octahedral sheets and constitutes $3 / 4$ of the $-\mathrm{OH}$ groups [40]. The water molecules in kaolin are detected by the presence of the $\mathrm{H}-\mathrm{O}-\mathrm{H}$ bending mode at approximately $1630 \mathrm{~cm}^{-1}[40-$ 43]. The wavenumbers between $400 \mathrm{~cm}^{-1}$ and $1000 \mathrm{~cm}$ 1 indicate the presence of $\mathrm{Al}-\mathrm{O}$ deformation vibration as well as Si-O bending vibration [40-43].

The gradual loss of intensity between wavenumbers 3600 and $3700 \mathrm{~cm}^{-1}$ of the $\mathrm{OH}$ stretching and bending bands in the IR spectrum of the kaolinite is a proof that de-hydroxylation is taking place leading to the conversion to metakaolin. Modification of structure on heating is observed by changes in the Si-O from plane stretch at $1109 \mathrm{~cm}^{-1}$ as a result of the adsorption valence vibration of $\mathrm{Si}-\mathrm{O}$ stretch. Wavelengths of approximately $792 \mathrm{~cm}^{-1}$ characterize the $-\mathrm{OH}$ translation in kaolin lattice [44]. The weak signal at wavelengths of approximately $1630 \mathrm{~cm}^{-1}$ is apparent only in the dehydrolysed samples indicating the vibration of water molecules [40-43]. The spectrum between 1300 and $400 \mathrm{~cm}^{-1}$ are normally used to show 
the structural features in zeolites. Calcination temperature has an effect on the spectrum of the zeolites as shown in the differences in the spectra of metakaolin samples calcined at $700^{\circ} \mathrm{C}$ and $900{ }^{\circ} \mathrm{C}$ respectively (Fig. 2c). Compared to the literature, the zeolite peaks are slightly shifted to lower wavenumbers $[28,45]$. The peak at $1001 \mathrm{~cm}^{-1}$ is attributed to asymmetric and symmetric stretching of the $\mathrm{Si}-\mathrm{O}(\mathrm{Si})$ and $\mathrm{Si}-\mathrm{O}(\mathrm{Al})$ bonds [28]. The wavenumber at 644 and $462 \mathrm{~cm}^{-1}$ are due to symmetric stretching vibrations of the double Si-O-Al bonds while the wavenumber at $555 \mathrm{~cm}^{-1}$ is due to bending vibrations of $\mathrm{O}$ - Si- $\mathrm{O}$ and stretching vibration of Si-O-Al bonds.

\subsection{X-ray Diffraction}

The XRD patterns for Ajebo and Darazo kaolin measured at room temperature are shown in Figure 3a. A lot of similarities exist in the intensities and positions of the Bragg angles for both samples. Based on the analyses, the phases identified in the Ajebo kaolin include $\mathrm{Al}_{2} \mathrm{O}_{9} \mathrm{Si}_{2}$ and $\mathrm{SiO}_{2}$ while for the Darazo kaolin; the identified phases include $\mathrm{Al}_{2} \mathrm{O}_{9} \mathrm{Si}_{2}, \mathrm{SiO}_{2}$ and $\mathrm{Al}_{2} \mathrm{O}_{3}$. After purification of the raw samples, the XRD patterns are dominated by the kaolinite peaks and the main characteristic peaks of kaolinite $\left(12.35\right.$ and $\left.24.88^{\circ}\right)$ can be clearly observed $[42,43,45,46]$.

The diffraction patterns of the metakaolin samples calcined at $900^{\circ} \mathrm{C}$ are shown in fig. $3 \mathrm{~b}$. The original structure of the clay mineral is broken in the process while the volatile matter present is removed. The resulting material readily accepts and exchanges ions in its structure as shown using equation 1.

$$
2 \mathrm{Al}_{2} \mathrm{Si}_{2} \mathrm{O}_{5}(\mathrm{OH})_{4} \underset{+4 \mathrm{H}_{2} \mathrm{O}}{\stackrel{600-900^{\circ} \mathrm{C}}{\longrightarrow}} 2 \mathrm{Al}_{2} \mathrm{Si}_{2} \mathrm{O}_{7}
$$

The disappearance of the diffraction peaks observed in the kaolin samples and the broad nature of the peaks in the metakaolin pattern are indicative of the transformation from a crystalline phase to an amorphous phase. The diffraction patterns for the zeolite-A from metakaolin calcined at $900{ }^{\circ} \mathrm{C}$ is shown in fig. 3c. The patterns for zeolites produced from both kaolin sources are similar with slight differences in their intensities. The patterns are very similar to that reported by Ugal et al., [27] produced from Iraqi kaolin. The diffraction patterns have very high crystallinity and based on the work of Chandrasekar [45], the measure of crystallinity can be estimated from the sum of the intensities of the 5 strong peaks $\left(21.8^{\circ}, 24.1^{\circ}\right.$, $27.2^{\circ}, 30^{\circ}$ and $34.3^{\circ}$ ). The patterns are also similar to the diffraction pattern for zeolite-A in the JCPDS database with the presence of the characteristic zeolite-A peaks $\left(2 \theta=7-18^{\circ}\right.$ and 21 to $\left.35^{\circ}\right)$ [47]. Any extra peaks in the patterns are possibly due to the impurities associated with silica in the original kaolin samples.
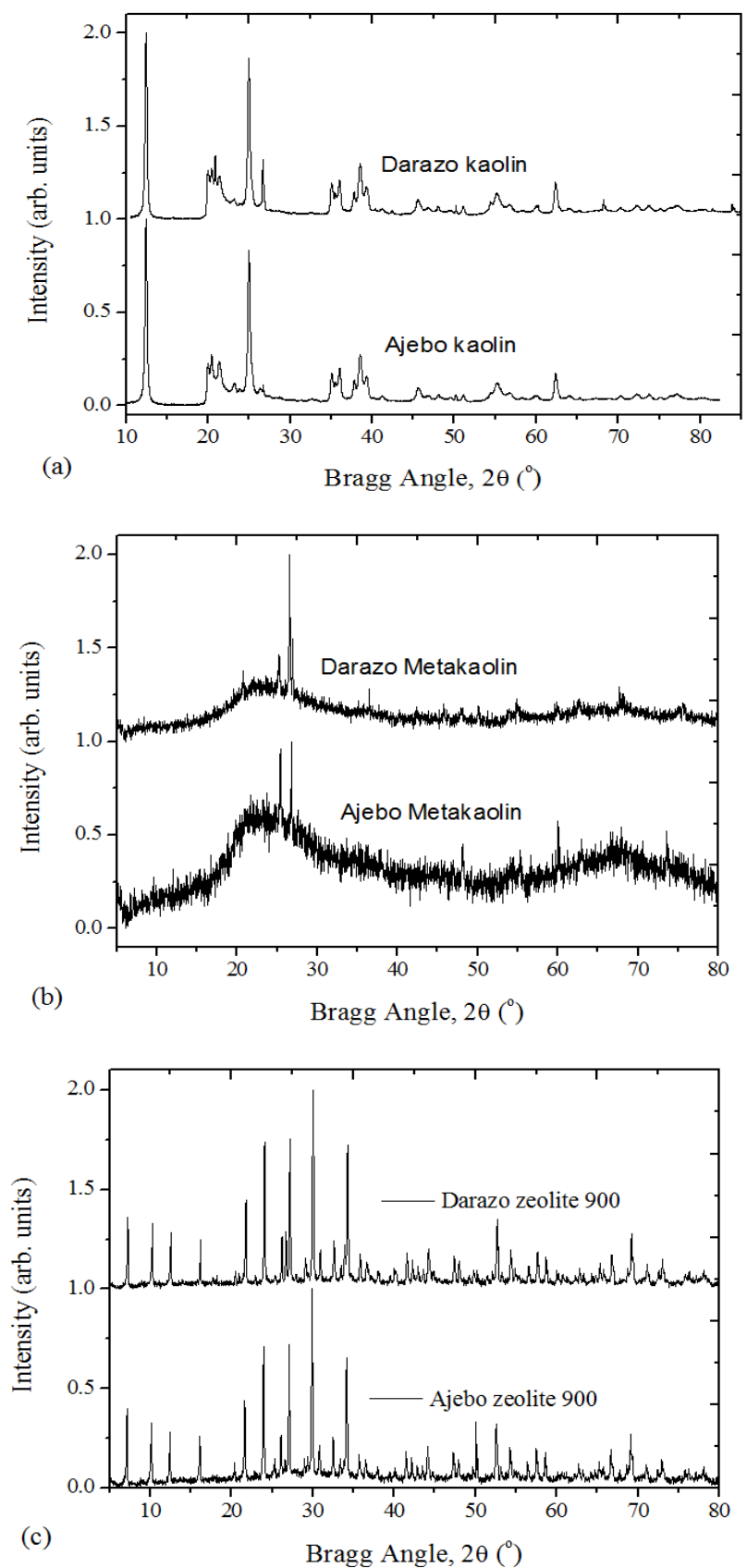

Figure 3: X-ray diffraction Patterns for (a) Ajebo and Darazo kaolin measured at room temperature. (b) metakaolin at $900^{\circ} \mathrm{C}$ and (c) Zeolite- $A$

\subsection{Thermal Analysis}

The TG/DTA plots of the kaolin samples from Ajebo and Darazo measured from $20^{\circ} \mathrm{C}$ to $700{ }^{\circ} \mathrm{C}$ on heating are shown in Figure 4. Both samples show very similar trends both in the TG and DTA measurements. The mass losses from the TG measurements are 11.39 and 10.83 wt. \% for the Ajebo and Darazo kaolin respectively. These values are in close agreement with the values of the loss on ignition (LOI) obtained from 
the chemical composition analysis in Table 2. The thermal heat capacity of the Ajebo kaolin is $-516 \mathrm{~J} / \mathrm{g}$ while that for Darazo kaolin is $-463.1 \mathrm{~J} / \mathrm{g}$. The onset of dihydroxylation is after after heating for 88.7 minutes for Ajebo kaolin and 88 minutes for Darazo kaolin.

The DTA curve shows the exothermic and endothermic reactions that take place as the samples are being heated or cooled from a high temperature. Exothermic reactions are observed before $60{ }^{\circ} \mathrm{C}$ and at approximately $520{ }^{\circ} \mathrm{C}$. The loss at $60^{\circ} \mathrm{C}$ could be attributed to the effect of dehydration due to physically adsorbed water while that of $520^{\circ} \mathrm{C}$ is due to loss of chemically combined water as the phase present transforms from kaolinite to metakaolin.

The thermal analyses results also indicate that the dehydroxylation of kaolinite starts from around $440^{\circ} \mathrm{C}$ for both samples.

\subsection{Scanning Electron Microscopy}

The Scanning electron micrographs of Ajebo kaolin, metakaolin and zeolite-A are shown in figures $5 a-5 c$ while the micrographs of the Darazo kaolin, metakaolin and zeolite-A are shown in figure $5 \mathrm{~d}$ - $5 \mathrm{f}$ respectively. The morphologies of the samples in each category are similar for the kaolin from Ajebo and Darazo. Kaolin samples typically have layered morphology and clusters of the kaolin are observed. Metakaolin samples are typically amorphous and have a morphology that appears to be spherical $[28,48]$. Raw materials used to produce zeolites have an effect on the size of the zeolite-A crystals. Naturally occurring raw materials like kaolin tend to favour the formation of big crystals most possibly because of the ions of many elements which are present as impurities [49].
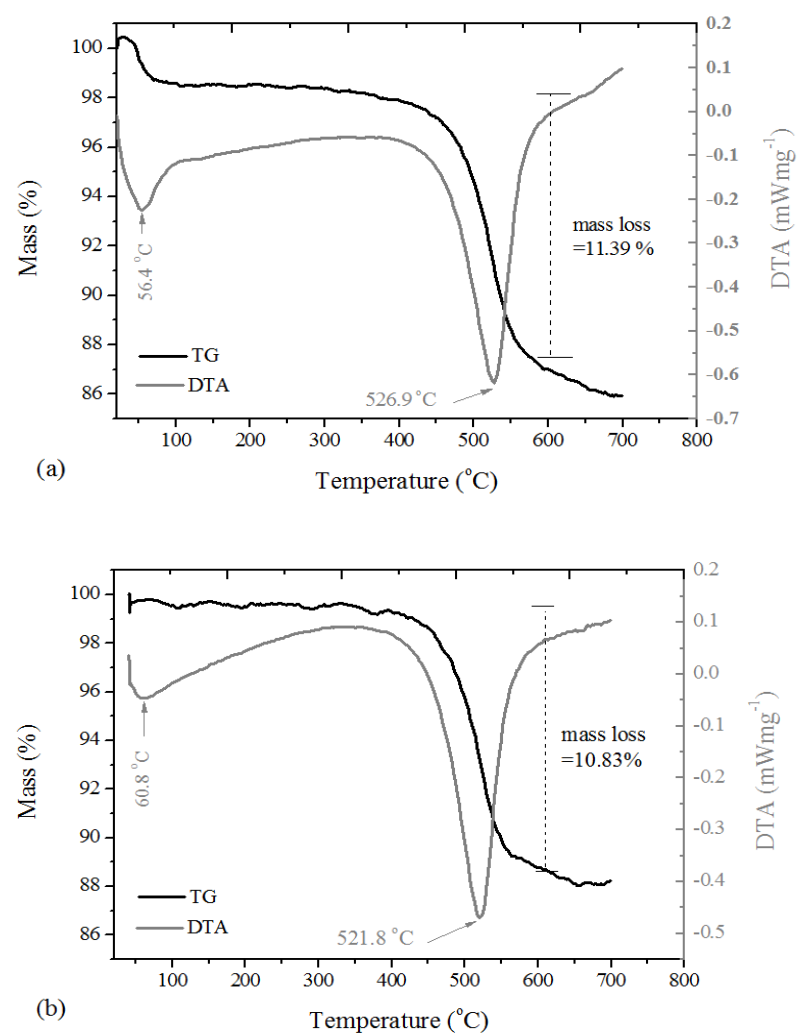

Figure 4: Thermogravimetric/Differential thermal analysis (TG/DTA) curves heating $20^{\circ} \mathrm{C}$ to $700^{\circ} \mathrm{C}$ for (a) Ajebokaolin and (b) Darazo kaolin.
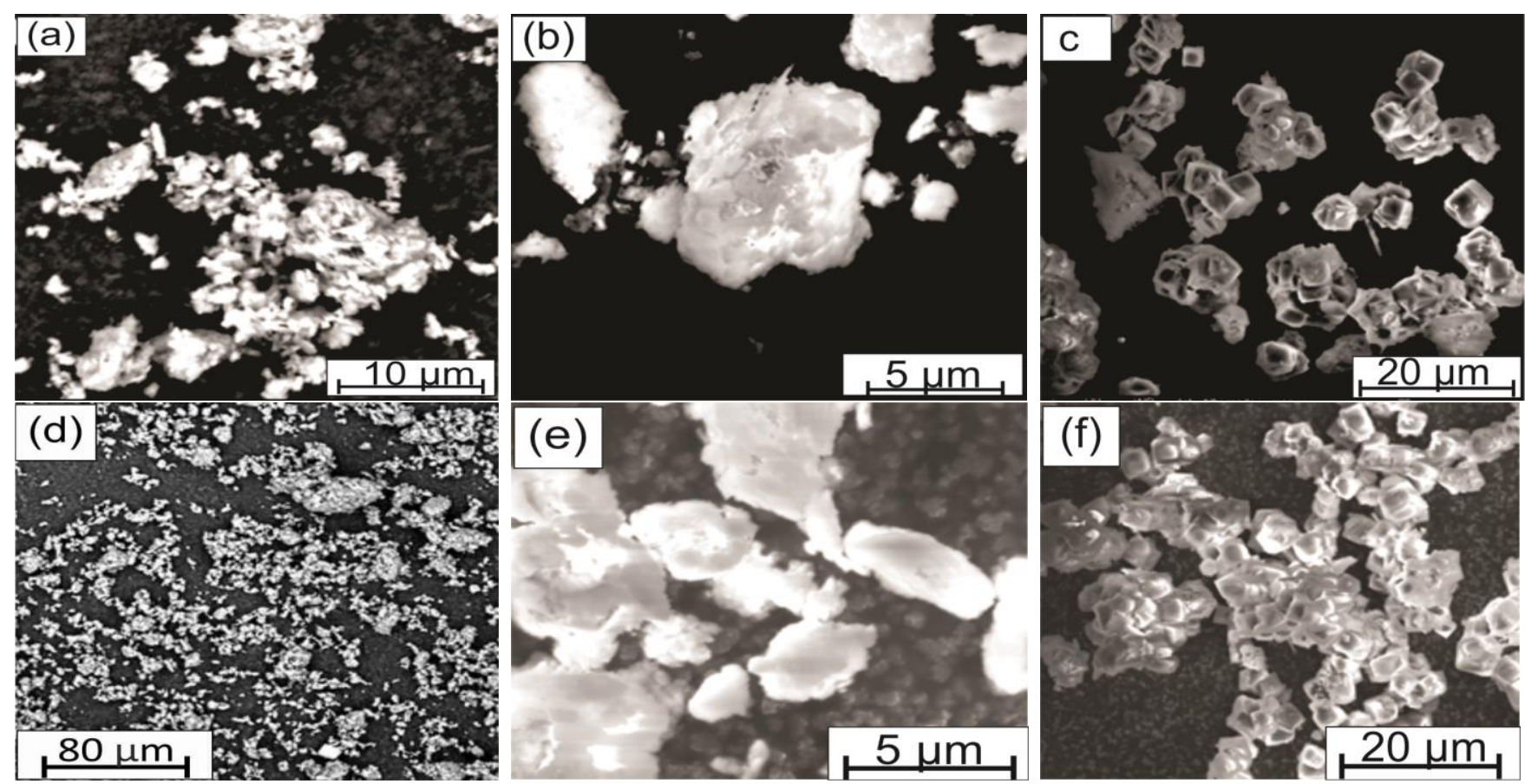

Figure 5: Scanning electron micrographs of (a) kaolin (b) metakaolin, (c) zeolite-A from Ajebo, (d) kaolin (e) metakaolin and (f) zeolite-A from Darazo kaolin 
Cubic crystalline structures with well-defined edges are observed on the micrographs of the zeolite-A samples. Aggregates of particles which are believed to come from the amorphous gel can also be observed. The expected reaction leading to the formation of the zeolite-A crystals according to Gualteri et al., [25] is shown in Eq. 2.

$$
\begin{aligned}
2 \mathrm{Al}_{2} \mathrm{Si}_{2} \mathrm{O}_{7}+2 \mathrm{NaOH} & +3 \mathrm{H}_{2} \mathrm{O} \\
& \rightarrow 2\left(\mathrm{NaAlSiO}_{4}\right)+4 \mathrm{H}_{2} \mathrm{O}
\end{aligned}
$$

The average size of the cubic shaped crystals for both zeolites is approx. $3.6 \mu \mathrm{m}$ which is large compared to similar zeolite-A from other sources. They tend to serve as nucleation sites for the crystals and also hasten the crystallization kinetics. The nature of the metakaolinite used to synthesize the zeolite can also determine the shape of the crystals as sodalite instead of Zeolite-A will be produce when kaolin or kaolin without complete metakaolinization is used [48]. The Si/Al ratio to some extent affects the shape of the crystals. According to Ismail et al., when the $\mathrm{Si} / \mathrm{Al}$ ratio is 1.5 , beveled as opposed to sharp well defined edges are obtained [50].

\section{CONCLUSION}

A bimodal grain size distribution is observed in both kaolin samples and their average grain sizes are less than $1 \mu \mathrm{m}$. The TG/DTA curves confirm the presence of kaolinite in both samples and the de-hydroxylation cycle on heating which is initiated from approx. $440^{\circ} \mathrm{C}$ and complete conversion to metakaolin is reached at a temperature of $540{ }^{\circ} \mathrm{C}$. A weight loss of 11.39 and $10.43 \%$ are observed for the Ajebo and Darazo kaolinite samples respectively. The FTIR spectra confirmed presence of the characteristic $-\mathrm{OH}$ stretching and bending which are characteristic of kaolinite samples as well as the $\mathrm{Al}-\mathrm{OH}, \mathrm{Si}-\mathrm{OH}$ and $\mathrm{Si}-\mathrm{O}-$ $\mathrm{Al}$ bands. The temperature of conversion slightly varies with that from the thermal analysis. The obtained spectra for the zeolite-A samples are similar to other zeolite-A in the literature. The XRD pattern clearly shows the presence of kaolinite peaks with the main characteristic peaks of kaolinite (12.35 and $24.88^{\circ}$ ) clearly observed. The patterns for the metakaolin and zeolite indicate that an amorphous and crystalline phase corresponding to zeolite-A crystals are obtained respectively. Well defined cubic crystals with sharp edges were obtained for the zeolite while an amorphous morphology was obtained for the metakaolin.

\section{ACKNOWLEDGEMENT}

The authors greatly acknowledge the financial support from the Central Research Committee of the University of Lagos under the grant: CRC 2016:14. Special thanks to the head of the Institute of Advanced Ceramics, Hamburg University of Technology, Germany for the opportunity to carry out the particle size analysis.

\section{REFERENCES}

[1] Konta, J. "Clay and Man: Clay raw Materials in the service of man," Applied Clay Science, vol. 10, pp. 275-335, 1995.

[2] Murry, H. H. "Traditional and New Application for kaolin, smercite and palygorskite: A general review," Applied Clay Science, vol. 17, pp. 207 221, 2000.

[3] Franco, F. Pérez-Maqueda, L. A.Pérez-Rodríguez, J. L. "The effect of ultrasound on the particle size and structure disorder of a well ordered kaolinite," Journal of Colloid and Interface Science, vol. 274, pp. 107-117, 2004.

[4] McClendon, J. H. "The Origin of Life," Earth Science, vol. 47, pp. 71-93, 1999.

[5] Osmanlioglu, A. E. "Immobilization of radioactive waste by cemetation with purified kaolin clay," Waste Management, vol. 22, pp. 481-483, 2002.

[6] Bhattacharyya, K. G. Gupta, S. S. "Adsorption of a few heavy metals on natural and modified kaolinite and montmorillonite: A review," Advance Colloid and Interface Science, vol. 140, pp. 114-131, 2008.

[7] Zuhua, Z. Xiao, Y. Huajun, Z. Yue, C. "Role of water in the synthesis of calcined kaolin-based geopolymer," Applied Clay Science, vol. 43, pp. 218-223, 2009.

[8] Wang, H. Li, H. Yan, F, "Synthesis and Tribologicalbehaviour of metakaolinite-based geopolymer composite," Materials Letters, vol. 59, pp. 3976-3981, 2005.

[9] Xu, H. Van Deventer, S.J. "Microstructural Characterization of geopolymer synthesized from kaolinite/stilbite mixture " Cements and Concrete Research, vol. 32, pp. 1705-1716, 2002.

[10] Rios, C. A. Williams, C. D. Fullen, M. A. "Nucleation and growth history of zeolite LTA Synthesized from kaolinite by two different methods," Applied Clay Science, vol. 42, pp. 446-454, 2009.

[11] Meftah, M. Oueslati, W. Amara, A. B. H. "Synthesis process of zeolite $\mathrm{P}$ using a pooly crystalline kaolinite," Physics procedia, vol. 2, pp. 1081-1086, 2009. 
[12] Letaief, S. Elbokl, T. A. Detellier, C. "Reactivity of ionic liquids with kaolinite," Journal of Colloid and Interface Science, vol. 302, pp. 254-258, 2006.

[13] Pinnavaia, T. J. "Polymer-Clay Nanocomposite," G.W. Beall (Eds.), John wiley\& Sons Ltd, 2000.

[14] Raw Materials Research and development Council (Federal Ministry of Science and Technology, "Non Metallic Mineral Endowments in Nigeria," 2010.

[15] Brindley, G. W. Robinson, K. "The Structure of Kaolinite," pp. 242-253, 1946.

[16] Karmous, M. S. "Theoretical Study of Kaolinite Structure; Energy Minimization and Crystal Properties," World Journal of Nano Science and Engineering, vol. 1, pp. 62-66, 2011.

[17] Militzer, B. Wenk, H.-R. Stackhouse, S. and Stixrude,L. "First-principles calculation of the elastic moduli of sheet silicates and their application to shale anisotropy," American Mineralogist, vol. 96, pp. 125-137, 2011.

[18] Young, R. A. Hewat, A.W. "Verification of the Triclinic Crystal Structure of Kaolinite," Clays and Clay Minerals, vol. 36, pp. 225-232, 1988.

[19] Research, F. M. "Kaolin Deposits and Mining in Nigeria: The Opportunity," 2012.

[20] Atta, A. Y. Ajayi, O. A. and Adefila, S. S. "Synthesis of Faujasite Zeolites from Kankara Kaolin Clay," Journal of Applied Sciences Research, vol. 3, pp. 1017-1021, 2007.

[21] Salahudeen, N. "Development of Zeolite Y and ZSM5 Composite Catalyst from Kankara Kaolin," in Department of Chemical Engineering. vol. $\mathrm{PhD}$ Zaria: Ahmadu Bello University, Zaria, 2015, p. 1311.

[22] Edomwonyi-Otu, L. C. Aderemi, B. O. Ahmed, A. S. Coville, N. J. and Maaza, M. "Influence of Thermal Treatment on Kankara Kaolinite," Opticon1826, vol. 15, pp. 1-5, 2013.

[23] Amber, I. Folayan, C. Suleiman, R. Atta, A. Y "Application OfSynthesised Zeolite A From Kankara Kaolin For Solar Adsorption Refrigeration," Journal of Mechanical Engineering and Technology, vol. 5, pp. 33-44, 2013.

[24] Costa, E. Lucas, A. D. Uguina, M. A. Ruiz, J. C. "Synthesis of 4A Zeolite from CalcinedKaolins for Use in Detergents," Ind. Eng. Chem. Res., vol. 27, pp. 1291-1296, 1988.

[25] Gualtieri, A. Norby, P. Artioli, G. Hanson, J. "Kinetics of formation of zeolite Na-A [LTA] from natural kaolinites," PhysChem Minerals, vol. 24, pp. 191-199, 1997.
[26] Miao, Q. Zhou, Z. Yang, J. Lu, J. Yan, S. Wang, J. "Synthesis of NaA zeolite from kaolin source," Front. Chem. Eng. China, vol. 3, pp. 8-11, 2009.

[27] Ugal, J. R. Hassan, K. H. Ali, I. H. "Preparation of type 4A zeolite from Iraqi kaolin: Characterization and properties measurements," Journal of the Association of Arab Universities for Basic and Applied Sciences, vol. 9, pp. 2-5, 2010.

[28] Zhao, Y. Zhang, B. Zhang, X. Wang, J. Liu, J. Chen, R. "Preparation of highly ordered cubic NaA zeolite from halloysite mineral for adsorption of ammonium ions," Journal of Hazardous Materials, vol. 178, pp. 658-664, 2010.

[29] Kovo, A. S. Hernandez, O. Holmes, S. M. "Synthesis and characterization of zeolite $\mathrm{Y}$ and ZSM-5 from Nigerian Ahoko Kaolin using a novel, lower temperature, metakaolinization technique," J. Mater. Chem., vol. 19, pp. 6207-6212, 2009.

[30] D4318-17, "Standard Test Methods for Liquid limit, Plastic Limit and Plasticity Index of Soils," West Conshohocken, PA: ASTM International, 2017.

[31] Hajjaji, W.Hachani, M. Moussi, B. Jeridi, K. Medhioub, M. López-Galindo, A. Rocha F. Labrincha, J. Jamoussi, A. F. "Mineralogy and plasticity in clay sediments from north-east Tunisia," Journal of African Earth Sciences, vol. 57, pp. 41-46, 2010.

[32] Madejova, J. "FTIR techniques in clay mineral studies," Vibrational Spectroscopy, vol. 31, 2003.

[33] Vaculikova, L. Plevova, E. Vallova, S. Koutnik, I. "Characterization and differentiation of kaolinites from selected Czech deposits using infrared spectroscopy and differntial thermal analysis," ActaGeodyn.Geomater, vol. 8, pp. 59-67, 2011.

[34] Ekosse, G. E.a.M., A, "Mineral thermochemistry of bentonite and kaolinite related to their possible application in the ceramic industry," Journal of Applied Science, vol. 8, pp. 4145-4151, 2008.

[35] Ekosse, G. E. "Thermoanalytical characterization, stable isotope and paleoenvironmental considerations of kaolinite from two genetic sources," Fresenius Environmental Bulletin, vol. 17, pp. 29-42, 2008.

[36] Saikia, B. J.Parthasarathy, G. "Fourier Transform Infrared Spectroscopic Characterization of Koalinite from Assam and Meghalaya, Northeastern India.," Journal of Mordern Physics, vol. 1, pp. 206-210, 2010.

[37] Kiros, A. Gholap, A. Gigante, G. E. "Fourier Transform infrared spectroscopic characterization of clay minerals from rocks of Lalibela churches, Ethopia.," International Journal of Physical Science, vol. 8, pp. 109-119, 2013. 
[38] Djomgoue, P. Njopwouo, D. "FT-IR Spectroscopy applied for surface clay characterization.," Journal of Surface Engineering Materials and Advanced Technology, vol. 3, pp. 275-282, 2013.

[39] Ece, O. I. Nakagawa, Z. Schroed, P. "Alteration of volcanic rocks and genesis of kaolin deposits in the Sile region, Northern Istanbul, Turkey.," Clay Mineralogy. Clays and Clay Minerals vol. 51, pp. 675-688, 2013.

[40] Cicel, B. Novak, I. Horvath, I. Mineralogy and Crystal Chemistry of Clays, vol. 1, 1981.

[41] Bich, Ch. Ambroise, J. Pera, J. "Influence of degree of dehydroxylation on thepozzolanic activity of metakaolin", Applied Clay Science, 45, pp. 24-35, 2009.

[42] Prost, R. Dameme, A. Huard, E. Driard, J. Leydecker, J. P. "Infrared Study of Structural OH in Kaolinite, Dickite, Nacrite, and Poorly Crystalline Kaolinite at 5 to $600 \mathrm{~K}$ "Clays and Clay Minerals, vol. 37, pp. 646-668, 1989.

[43] Frost, R. L. Vassallo, A. M. "The Dehydroxylation of the Kaolinite Clay Minerals Using Infrared Emission Spectroscopy" Clays and Clay Minerals, vol. 44, pp. 635-651, 1996.

[44] Zhang, Z. Yao, X. Zhu, H. S. Hua. Chen, Y. "Activating process of geopolymer source material: Kaolinite" Chem: Journal of Wuhan University Technic, vol. 24, pp. 132-136, 2009.

[45] Chandrasekar, S. "Influence of Metakaolinization Temperature on the formation of Zeolite $4 \mathrm{~A}$ from Kaolin," Clay Minerals, vol. 31, pp. 253-261, 1996.
[46] Panda, A. K. Duncan, J. F. Foster, P. K. "Effects of Sulfuric Acid Treatment on the Physico-Chemical Characteristics of Kaolin Clay. ," Colloids and Surfaces: Physicochem. Eng. Aspects, vol. 363, pp. 98-104, 2010.

[47] Sanhueza, V. Kelm, U. Cid, R. "Synthesis of molecular sieves from Chilean kaolinites: 1. Synthesis of NaA type zeolites," J. Chem. Technol. Biotechnol., vol. 74, pp. 358-363, 1999.

[48] Reyes, C.A.R., Williams, C. V. Alarcón, O. M. C. "Synthesis of zeolite LTA from thermally treated kaolinite," Rev. Fac. Ing. Univ. Antioquia, vol. 53, pp. 30-41, 2010.

[49] Petkowicz, D. I. Rigo, R. T. Radtke, C. Pergher, S. B. Santos, J. H. Z. d. "Zeolite NaA from Brazilian chrysotile and rice husk," Microporous and Mesoporous Materials, vol. 116, pp. 548-554, 2008.

[50] Ismail, A. A. Mohamed, R. M. Ibrahim, I. A. Kini, G. Koopman, B. "Synthesis, optimization and characterization of zeolite A and its ion-exchange properties," Colloids and Surfaces A: Physicochem. Eng. Aspects, vol. 366, pp. 80-87, 2010.

[51] O. A. Ajayi. S. S. Adefila, M. T. Ityokumbul, (2017) Organic Template free Synthesis of ZSM 11 from Kaolinite Clay, Nigerian Journal of Technlology, 36(2) 444-451

[52] S. G. Bawa, A. S. Ahmed, P. C. Okonkwo, (2016) The Study of Thermal effect on the Surface Properties of Gamma-Alumina Synthesized from Kankara Kaolin, Nigerian Journal of Technlology, 35(1) 6670 